\title{
The Limits of Identity - Performativity, Gender and Politics
}

\author{
Kerstin Jergus \\ University of Fribourg, Department of Educational Sciences
}

\begin{abstract}
This article explores the limits of identity in the context of gender policy. From a linguistic-philosophical perspective, the first question is how identity is created and under what practical conditions it becomes effective. In light of these considerations on the relationship between identity and social order, matters of recognition and normalization are discussed. These outlines are then related to current gender policies in the university area. The boundaries of identity and the political dimensions of speech acts lead to the question how critical and resistant speech can take shape.
\end{abstract}

Keywords: Butler, Recognition, Derrida, Subjectivation, Critique

\section{Les limites de l'identité - Performances, Gender et Politique}

Résumé: Cet article explore les limites de l'identité dans le contexte de la politique de gender. D'un point de vue linguistique et philosophique, la première question est de savoir comment l'identité se crée et dans quelles conditions pratiques elle devient effective. À la lumière de ces considérations sur la relation entre l'identité et l'ordre social, les questions de reconnaissance et de normalisation sont abordées. Ces grandes lignes sont ensuite liées aux politiques actuelles en matière de gender dans le domaine universitaire. Les limites de l'identité et les dimensions politiques des actes de langage amènent à se demander comment un discours critique et résistant peut prendre forme.

Keywords: Butler, Reconnaissance, Derrida, Subjectivation, Critique

\section{Los límites de la identidad - Rendimiento, gender y política}

Resumen: Este artículo explora los límites de la identidad en el contexto de la política de gender. Desde una perspectiva lingüístico-filosófica, la primera pregunta es cómo se crea la identidad y bajo qué condiciones prácticas se hace efectiva. A la luz de estas consideraciones sobre la relación entre identidad y orden social, se discuten cuestiones de reconocimiento y normalización. Estos esquemas se relacionan con las políticas de género actuales en el ámbito universitario. Los límites de la identidad y las dimensiones políticas de los actos de discurso llevan a la pregunta de cómo puede tomar forma el discurso crítico y resistente.

ISSN 2560-8371 
Keywords: Butler, Reconocimiento, Derrida, Subjetivación, Crítica

\section{Introduction}

The importance of identity is currently experiencing an enormous revaluation - despite or precisely because the question of belonging is increasingly becoming an object of political and private negotiation due to globalised capitalism, global migration processes and transnational politics. Political struggles and political movements are formed along and through recourse to questions of identity. It seems as if at present the reference, evidence and assignment of an identity is capable of moderating the social and political issues at hand in a way that apparently gives relevance to all possible forms of nationalism, sexism, racism and culturalism in a new way through narratives of identity and offers of identification. It should be underlined here that such ideas and references to identity have always played a role in Western European modernity. Nevertheless, very different problem areas and heterogeneous social and political aspects show a new sharpness and a new intensification of identity issues. Politics in the name of identity indicates the mobilizing power of belonging, which in different directions makes the necessity of positioning in existing offers of identity seem inevitable. It seems easier to talk about sexualized violence in public fields, which is structured by power relationships that are gender-associated, by personal testimony and taking sides, as the keyword "Me too" shows. Party frameworks and expressions of sympathy, as well as self-identification as affected persons are important for a public debate, but they also have the consequence that the area of understanding about the existing inequalities and power relations is located at the level of personal concern.

Another level of current politicization, driven and moderated by questions of identity, can be seen in an increasing nationalization of political problems, which not least enables personal identity as belonging to a certain group to decide on life and death.

In the following explanations, identity is not considered as an ontological or substantial quality that could justify an entity or essence of the individual. Rather it will be considered that any identity depends on speech acts, on social categories and on cultural practices. Identities do not exist per se, before or after their narrative, practical and social instituting. This is nowhere more evident than in gender identity, which will be the focus of the following explanations of the relationship between subjectivity, identity formation and politics. The first step is to focus on the power of language, which determines the development of the individual as part of social relationships of belonging. In a second step, the connections between gender identity, social position and pedagogisation are brought to the fore by discussing the example of gender equality instruments. The third step reflects on the question of the conditions and possibilities of critical speaking that emanate from the limits of identity.

\section{The Power of Language - The Performative Dimension of Identity Formation}

"We do things with language," writes the American social philosopher Judith Butler (1997, p. 7), "produce effects with language, we do things to language but language is also the thing that we do. Language is a name for our doing." With this passage Judith Butler draws attention to the fact that language does not only reproduce and formulate things that had already existed as reality 
before, but that speaking itself is an action. This insight was elaborated under the term 'performativity' by John L. Austin's (1962) linguistic analyses, to which Butler's considerations refer. Through language ideas are created, perspectives are formed, opened or even limited. But it is not only the imaginative and cognitive levels that make up the sphere of action of language. The way in which we address someone or are addressed by someone, the words with which we think and encounter someone or the images and ideas that surround us have an impact on who we are and how we perceive our counterpart. This is particularly noticeable to us when we are addressed and touched heartily and benevolently, as it also becomes clear to us when others treat us disparagingly or disrespectfully. Language therefore has a strong effect; it creates realities, it does not only depict them. But how does this simultaneity of action and effect work?

This can be read almost like a "primal scene" in the act of birth naming. It is usually a midwife or a doctor who calls "It is a girl," after which the newborn baby is given a name. With the naming an identity is given, the newborn child becomes someone. This naming, which takes place without the consent of the newborn, which is thus in the truest sense of the word a "gift," cannot be revised. You can only relate to this first act of giving identity later, for example by changing your own name or replacing it with nicknames or being addressed by others with names. But even all these overwritings and replacements cannot reverse the act of giving identity - the nomination in the act of naming which is our entry into the social life of relationships and belonging. It will always be part of the stories that an individual experiences about her- or himself, that she or he passes on to others about her- or himself. The fact that our name and thus an important part of our identity does not come from ourselves but has come to us from others also implies that a large part of our identity is beyond our reach. Others have determined who we are and how we enter the world. From the beginning, our identity depends on others. Our becoming and our arrival in the world were already discussed and expected before our birth. Names and ideas, wishes and fears were connected with our person even before we were even able to say "I." So there are basically parts of ourselves that remain alien to us, which we will subsequently acquire, as stories of parents, relatives and friends who began before and during our birth without our help.

But it is not only in relation to the individual identity that the power of language can be seen in the act of naming. As in most cases, a gender identity is also assigned to the name and usually the name also belongs to a specific language culture or milieu. Thus, the name confers both an individual identity and a social identity. The social part of identity consists, for example, of belonging to one of the two gender categories, to a social group or to a social origin marked by the name. In this way, the speech act of naming not only gives an individual identity, but also renews the order of gender or origin.

This connection of language action and its effects is called performativity. It goes back to the language theorist John L. Austin, whose lectures on this topic can be read under the title "How to do Things with Words" (Austin, 1962). Austin examines those cases of language acts "in which by saying something or in saying something we are doing something" (ibid., p. 12). Austin considers baptism or marriage to be one of these cases. In these cases, the power of spoken language can be particularly well demonstrated: In the act of marriage or baptism, with the words "Herewith I declare you..." or "Herewith I baptize you..." a speech act is carried out which does not only subsequently name something that would already have existed. A registrar or a priestess does not simply prove by her words something that was already valid before these words. They 
create with their utterances what the words denote. Consequently, these acts of speech cannot be treated in a "right/wrong" manner (such as the phrases "it rains" or "the sky is grey," which Austin calls constative acts of speech). Performative speech acts carry out a new reality in the act of speaking. Baptism or marriage gives persons a new identity with all personal and legal consequences resulting from marriage or belonging to a religious community.

Austin points out for these cases of performative speech acts that certain conditions are necessary for their accomplishment. What is needed is a specific context, including legal frameworks and certain elements, such as the baptismal font or the civil register, passport documents and possibly also wedding rings, which make it possible to carry out the act. A speech act such as baptism or marriage is therefore based on conventions that have been passed down socially and culturally. In particular, the conditions of success of such speech acts include the requirement of an authorised person who is entitled and authorised to carry out these appointments (as a girl or boy, as a baptized person, as a spouse). This can easily be explained by the fact that during birth, for example, a big sibling of the newborn child could also interject: "But it is a boy!" This speech act also has effects, of course, but has no effect on the sexual identity of the newborn, which is determined by the midwife or the doctor. It is also conceivable that small children could play wedding and say to each other: "You are my husband now," which has no legal consequence as married persons.

The sociologist Pierre Bourdieu (1991) has described these effects of linguistic actions as "social magic," which is also used in other acts of naming, such as the awarding of titles or examinations. Examinations confer identities insofar as new and other social spheres of action can be entered after passing an examination and obtaining a title (for example through licensure, priestly ordinations, political offices, etc.). Admittedly, a person can be awarded professional aptitude in a variety of forms. However, providing a person with powers and access to, for example, the labour market or social positions requires specific rites such as final examinations, exams or tests. Through such frameworks does the pronounced recognition unfold its effect with regard to a person's identity as "examined," "legitimated," "authorised." The acquisition of such titles or authorizations, in turn, opens up new opportunities for the individual to act - even if an exam has scarcely been passed. Such speech acts lead therefore to a 'new' identity in two respects: the person acquires a different status in the social realm, the person is perceived and endowed as 'entitled' with all rights, obligations and expectations. And through being addressed as such (legitimated or examined) she or he is also empowered to understand herself or himself as capable of acting and authorized. The social identity entails a specific self-relation.

This also means that recognition does not only have an effect if it is expressed and experienced as a positive act of appreciation or as a laudatory confirmation. Dismissals, denominations and humiliations also have effects on the self, confirming someone as 'rightless,' 'insignificant' or 'worthless'. Recognition therefore has a twofold dimension, namely to create an identity - in whatever respect. The foundation and the confirmation fall into one and are bound to linguistic terms, speeches and offers of identity. It is not only the contextual conditions and authority figures that are so important for Austin that make linguistic actions effective. An identity is far more fundamentally dependent on perception (recognition) and confirmation (recognition) by others.

Recognition does not only take place in the medium of speech, it is also integrated into linguistic patterns and frameworks. Being addressed as someone - as a girl, as a woman, as a 
scientist, etc. - also limits the possibilities within which a life can be lived as a girl, as a woman or as a scientist. It is not at the will or power of the individual to choose these norms and frameworks or to shape them entirely at his or her own discretion. Rather, language comes to the individual - as in the birth act of naming, it is first and foremost in the literal sense: an address. Thus, the condition of existence of the individual is being addressed. All those acts of appealing in which the self is addressed as someone are of importance for self-formation. The self does not arise out of itself, its beginnings and origins lie in the other. For this reason, the Self is always receptive and open to others. Individuals are not only addressable, they are also vulnerable. Disrespectful, hurtful or contemptuous speeches also have an effect on the identity of the self, precisely because we are fundamentally dependent on recognition by others in our existence.

The effects of speech actions therefore imply an existential dimension in every respect. Acts of speech call an individual into a social space, into a language community, a cultural and social matrix whose form is not in the hands of the entering individual. Actions of speech thus create every personal identity as one associated with social norms and frameworks.

The birth naming already showed that acts of identity conferment not only have personal consequences for individual identity. A name or title always has a socio-cultural side. They have an impact on the social place of the individual in the world. Thus, it still makes a considerable difference in terms of possibilities and limits of personal lifestyle and access to social spaces to which one belongs and is assigned to the two gender categories. Personal and professional options, limitation and opening of possibilities and not least the likelihood of being affected by humiliation or experience of violence are directly related to gender conditions, as can be seen not least in the cases of sexualised violence against women that are currently being made public.

But it is not only in this respect that the power of language can go hand in hand with violence. Names and speeches, however thoughtless or extremely weighed they may be, they always have a quite powerful quality, which the addressed individual is powerless against. The person addressed or the person named can only react to having been addressed in this way. Paradoxically, in speeches, powerlessness and empowerment fall into one: As a so-and-so-named person, I can react defensively or happily to this name, I cannot undo it. And this applies both to very personal speeches as a concrete person and to general categories and frames in which we have to find ourselves as one self. The violent dimension also lies in the name itself, as it is a selection and thus excludes other possible terms. Therefore, it may only make a small difference, but it can be a difference around the whole if certain groups of people are already excluded verbatim from public spaces or are not named as part of public spaces. Often verbal humiliations or denominations of physical threats and physical violence violence. As is particularly evident in the context of sexualised and racist violence, physical threats and violence are also directly related to linguistic terms.

\section{Gender identity policies in the university field}

Gender policy in higher education is a particularly complex field in which the interdependence of subjectivity, recognition and norms can be revealed. At this point it would lead too far to shed light on the more far-reaching historical processes connected with the genesis of the production of scientific knowledge and its gender connotation. Such a quest would require a more detailed examination of the androcentric knowledge culture. It might be starting in the Greek paideia and its close relation to the Eros as a drive for knowledge and education, and would at least have to 
reach up to the supposed universalism of Western European ratio and its involved androcentric dimensions. In this line has to be remarked, that part of feminist movements over the last 150 years has been the political demand for participation in public areas, primarily politics and the market, but above all in the area of education. In the course of the establishment of modern orders of Western European shape, the liberal-state division of spheres between private and public areas was embedded in a gender order that not least regulated the possibilities and limits of access to education and the public sphere for the sexes: While the private sphere as a female sphere was separated from the public sphere of human affairs (and this shows that this division of spheres between the oikos and the res publica encompasses a much longer tradition), both rebelled against each other and were closely connected with modern pedagogy. The emergence of free individuals, which was to be provided by public education in the liberalist nation-state model, was based on education to be provided by maternal care and concern.

Against this background, the feminist dispute over participation in public fields had far more to achieve than formal access rights. The subject matter and obstacle was something completely different from what the administrative act alone would now have to do to issue voting cards and access authorisations to another part of the population. For the demands of the women's movements touched the level of knowledge about the possibilities and the nature of women as human beings. In this respect, the feminist movement and the struggle for women's participation in public spheres was also and primarily a commitment to knowledge and truth politics. The idea that women are less able to understand, represent and shape public affairs had to and sometimes has to be irritated and questioned at present. The long struggles for girls' education and to enable women to work always had to argue against the idea that girls and women are not as biologically, anthropologically or genetically capable as men of education and employment.

It is therefore not surprising that the university, as a place of knowledge and knowledge production, was and is one of the most important venues where these struggles took place, were successful and still have to do with the persistence of traditional gender orders. One of the most central strategies of argumentation to date is the scandalisation of representation, in that the proportions of women and men in the entire population are shown to be unequal in relation to their distribution in public fields. In this line of argumentation, statistical data show that there is a mismatch between the participation of women in public areas and their proportion of the total population.

Although this form of criticism of gender discrimination is an important instrument of politicisation, it also includes the problem of normalising reification: The figures vitalise the order of the two sexes and ignore the differences between the 'women' mentioned here as a unified group. Socio-cultural backgrounds and resources such as cultural and social capital are just as concealed in their valence for career opportunities as is the overall interplay between institutional logic (here: the university with its specific selection, performance and promotion logics) and the relevance of gender differences. The existence of gender differences, on the other hand, is (presumed) to be significant for participation in the academic world.

Until the 1990s, the central task of political-feminist advocacy was the explicit promotion of women. As a result of the feminist theoretical debate on the tendencies of association interpretation and exclusion procedures in the reference to the category 'woman,' a new political focus on the objectives of equality and equal opportunities also became crucial. With this change, 
the form and orientation of the political project changed: The area of responsibility of gender equality work expanded to areas such as anti-discrimination work, family policy measures as well as more advisory and educational work on issues of sexualised violence through the explicit promotion of women. Moreover, in the recent past, gender equality work has become an area strongly determined by economic motives in the course of the introduction of new governance logic in many public areas. Equality standards are increasingly becoming relevant aspects of the competitiveness of institutions that establish incentive structures and competitive logic through the allocation of funds and quality management. As a result, gender equality work within the framework of this entrepreneurially oriented logic of New Public Management is seen as an investment in the absorption of all available resources and is increasingly professionalized in a human capital-oriented perspective (Casale \& Forster, 2011).

This is particularly evident in the connection between the promotion of women and the diversity management instruments anchored in many public institutions. As in the diversity programmes from corporate cultures, performance is hereby not only naturalized but assigned to particular subjects (Freithofer \& Hollerwöger, 2008). At the level of diversity management, two sexes - like any other category marked as a difference - are regarded as essencialized. As a result, the associated assignments of compatibility concerns, reproduction issues and risk situations are not questioned, but treated at the level of (managerial) 'dealing with...' The underlying gender orders and the resulting inequalities are lost sight of. This leads to ratification of inequalities in the reference to gender (as well as to other dimensions of difference such as class or ethnicity). The social dimension of the production, reproduction and participation of institutions in the emergence of differences and their values remains thereby dethematised. These arguments are underlined by migration education research on the practices of "institutional discrimination" (Gomolla \& Radtke, 2009). The findings show that in dealing with educational deficits a specific individual-centred perspective on acts of discrimination is very often adopted: Discriminating people are treated as prejudiced actors and discriminated people as addresses of compensatory integration and promotion measures. In this way, the institutional logic and discursive effectiveness of norms, institutions and organisations is systematically ignored.

This whole problem is exacerbated by the specific pedagogical logic of gender equality instruments. They call on women to see themselves as subjects in need of support, whose place is not assigned or has yet to be won. This is intertwined with a specific probationary dynamic of the academic system, which equates career suitability and performance. As a result, career paths are treated as individualized actions of success or failure, without even having to make the structural conditions or the unequal distribution of resources an issue.

From the criticism of empowerment processes, the argument can be transferred at this point that the concern and practice of empowerment always rests on the imputation and assignment of powerlessness (Bröckling, 2004). Promoting women or placing them in the focus of gender equality policy addresses them as individuals in need of support. From a deficit-led perspective, the need for help is not only imputed, but also cemented, resulting in an ongoing need for pedagogical work to optimize the self. Practices of promoting and activating individualize and depoliticize as a consequence the structural and institutional problems that arise through unbounded and neoliberally structured working environments. Professions thus appear alone as careers that can be continually optimized in entrepreneurial self-management 
logic (Bröckling, 2007). For the promoted individuals addressed in this way, the work on optimizing their self seems all the more unavoidable and desirable, insofar as the alternative to advancement very often goes hand in hand with exclusion through exit.

In this way, gender policy runs into a paradoxical relationship to normality and normalisation: the determination of inequalities does not only refer to normative categories such as gender. It also aims at a normalisation of distribution proportions. The policy of equality gains the starting point of its normalisation practice and the desire for a different normality in the concern for a normalisation of distribution relations (Jergus, 2015). The reference point of this aspiration for normalization is linked to representativeness referring to population categories. Those Categories are then no longer questioned regarding their normedness. This also applies to other categories such as nationality, ethnicity and socio-cultural origin, which are highly controversial at the scientific level due to their normativity and discrimination dimension, but which are crucial for strategies of measurement and also with regard to discrimination-sensitive ways of dealing with social inequalities.

The use of gender studies, which is critical of knowledge and thus also of the academic realm, is concerned with extending and changing the norms of recognisability of what can claim validity as scientific knowledge, as scientific cognition, as scientific practice and as a scientific subject. Theoretically and politically speaking this involves the achievement of visibility and recognition. This connection between recognisability and recognition, to which reference has already been made above, renews the insight that recognition processes are not limited to the normative demand for appreciation and affirmative praise alone. Critical continuation of the strongly normative concept of recognition is therefore helpful for this aspect. The problem with a narrowly defined concept of recognition, as found in Honneth (1995), for example, is that the social conditions of recognition are lost sight of (Hetzel, 2011). The connection between visibility and recognition is not analyzed as discursively and socially generated standardization, but only localized on the individual level of intentional acts of praise and appreciation (Butler 1997a; Ricken \& Balzer, 2010).

Judith Butler therefore argues that recognition is always intertwined with norms of recognisability. In this context, she points to a "complicity" (Butler, 1997a), which arises through the recognition of these norms in the process of subjectivation and creates a desire for "conformity" (ibid.). The desire to be a recognizable subject means that a critique of norms also endangers the complicity of subject and norm.

The contouring of zones of the acceptable also figures the area within which the status of a subject can be assigned. These zones of recognition result, as Michel Foucault's studies have shown, from normalisation practices such as those produced and differentiated categories such as gender, health, reasonableness, etc. by modern scientific anthropology and research (Foucault, 1970, p. 1978). Zones of the acceptable and thus the limits of the normal are established by demarcations to an outside, resulting in a 'tendential emptiness' of norms or an unfulfilled normality area. Norms do not exist outside or in front of the individual subject, they have no 'pure' status, but are practically installed through processes of subjectivation. In this necessity of repetition, Butler uses Derrida's epistemological arguments to work out the notion of the unfulfilled norm. The unfulfilledness of the norm generates the desire to be a recognizable subject and the complicity between subjectivity and normality. At the same time, this should be emphasized here in advance of the concluding section, Butler locates the possibility of resistance, 
subversion and change in this unfulfilled state and the resulting necessary repetition and reinstitution of the norms (Butler, 1997b). Desire of the norm is thus directed in two ways towards "the promise of the norm" (Butler, 2003, p. 64), in that both the existence of the subject and the existence of the norm are contained therein - and permanently suspended.

Norms of recognisability therefore affect the discourses on gender orders in the field of the university in two ways: It is the criticism of the logic of representation and the associated unification of the world in men and women - with consideration of internal differences, interference and superimposition with questions of social and national-ethnocultural logics of origin and affiliation - that constitutes the epistemological framework of problematization and the use of gender studies in scientific theory. Through the reference to a binary gender order contained in the logic of promotion and equality, however, femininity and masculinity are related to each other as if they were intrinsically naturalized. As a result, questions of reproduction, care and responsibility are reconsidered in their gendered allocation. A close relationship to the biopolitical focus of the population, which is regarded as a measure of representation, plays a role here. On the basis of the practices of promoting women, it can be observed that the scientific and political areas of debate diverge. This is quite functional for the maintenance of existing orders, especially the hierarchical logic of advancement and career and entrepreneurial selfmanagement practices. In this sense, the logic of promotion becomes an instrument for activating the isolated individual to struggle for recognition, to become recognizable and to be recognized as a promotion-subject. Support instruments call on women to optimize their careers in science and research within the order of advancement. The promotion logic then also makes it possible to attribute failure not to conditions but to individuals. This shows how promotion logic in the reference to gender maintains the order of status and probation.

They furthermore work with and employ a specific educational approach: career coaching and counselling services for women are aimed at changing the individual women who are to be made fit and capable of competing, while educational and professional paths as well as the illusion of equal opportunities therein (cf. Bourdieu \& Passeron, 1990) can remain largely unquestioned. The political problem of social inequalities and structural disparities of the actors' respective resources are transferred to competition and the optimization of biographies. Educational science research has repeatedly pointed out how pedagogization contributes to the depoliticization of social problems by transfiguring political and social grievances into a change of self (Tröhler, 2016).

In the light of this, doubts can be cast on promotion and equality policies. The question is to what extent and whether the promotion logic of gender equality work possibly keeps the division of social space alive by assigning masculinity and femininity (and correlatively: top and bottom). This is done above all by detaching the questions of participation and reconciliation problems as well as the socio-structural obstacles and diverging resources of individual actors through the instruments of the promotion of women and equality. It is therefore possible that gender equality work plays its part in these disparities, insofar as the question of being part of social and cultural fields, especially in the area of wage employment, is depoliticised in a specific way. In this way, inequalities are authorised - paradoxically precisely because women's instruments and instruments of equality are increasingly being used. In view of the continuing unequal access conditions to socially relevant areas, the question can in any case be raised as to 
what kind of effectiveness emanates from the promotion instruments of gender equality work, which primarily shows itself as a depoliticisation of the disparity processes.

\section{Impure language, critical practice and struggles at the borders of identity}

Even if the speaking power of individuals always is depending on the powerlessness towards language, the performativity of language also offers the possibility of opening up other ways of speaking and thus of other realities. Precisely because utterances do not only depict what would already be there anyway, language is able to create other realities and new offers of identity. If language gives life to people, things and realities by naming them, then a way of speaking other than the recognized or accepted way can be used at any time. It is always possible to describe people and things differently than they are supposed to, differently than expected, differently than desired. People, things and facts can have a different status in the social sphere, a different meaning in the world or a different place in order through other terms. As few individuals and memberships are protected from any verbal embarrassment or injury, the previously accepted and traditional conditions are protected from their new accentuation or shift. It is part of political and social conflicts to struggle for the meaning of words and the realities they create.

This can be combined with the question of criticism and the possibilities of another, of critical speaking. Judith Butler's approach, which links "the political promise of the performative" (Butler 1997b, p. 162) with the question of critique, can be taken as a starting point. Butler refers to the openness of the term with the keyword 'resignification.' By relying on Jacques Derrida's argument that any meaning can only be acquired through exclusion and therefore remains unstable (Derrida, 1977), Butler takes the necessity of repetition as a reference point for thinking about the openness of the future (Butler, 1998, p. 256). Each speech links elements of discursive terrain to meanings, which, however, cannot be completely fixed, but must always be processed and maintained anew. The establishment of meanings thus remains dependent on their repetition, it remains open and eventful. Butler thus expands Derrida's semiotic view that meaning about the disruption with context is made possible to the question of the identity and order of the social. The source of a concept of critical or resistant thinking will be the fragility and the openness of any order, in that the strategic attempt can be made for "speaking in ways that have never yet been legitimated, and hence producing legitimation in new and future forms" (Butler, 1997b, p. 41).

With this ambiguous figure of the impossible possible, Butler turns against a generality that would deprive the singularity of any speech of its political possibilities. In this sense, in dealing with hate speech and the prohibition of pornography, she questions the legal procedures of sanctioning, for example, with regard to their own form of violence. It is not only disturbed by the fact that a sanction is always also a recognition (and thus itself a political act of giving meaning) and tries to establish the powerful sanctioning of purity regimes. She is even more critical of such an approach that it limits its own political agency by enhancing the state power and expanding its territory (Butler, 1997b, p. 28-30). Butler sets the openness of the term against the fixation of terms, as it would be necessarily a legal procedure, in that it would have to distinguish correct/appropriate from incorrect/forbidden speaking. The term requires rearticulation, constant processing and practical correlation. In Butler's view, this openness of the term, to which all speech must refer in and out, implies the political promise of a future that is understood as radically indeterminate and open: "That the term is questionable does not mean 
we ought not to use it, but neither does the necessity to use it mean that we ought not perpetually to interrogate the exclusions by which it proceeds" (Butler, 1993, p. 222).

Following Foucault (1992), Butler thus develops a perspective on the possibilities of critical speaking, which focuses on the 'non-identity' (Adorno) of the term and seeks to question its effects on truth and identity by 'working on the term' (Adorno). The practice of criticism takes its cue from complicity, which binds us to the terms on whose behalf criticism is voiced. The fact that 'criticism,' like any other term, cannot in itself acquire a definition of what meanings it implies, what contexts it can produce and what efficiencies it achieves, is an imponderability as to whether our speaking serves the factuality of the social order: "Including the political signifier (which is always a matter of including a signifier from whom one is already included, constituted, initiated) means being included in a chain of previous uses, amidst significations that cannot be classified according to clear origins or ultimate goals" (Butler, 1995, p. 300).

However, if the terms in which we understand ourselves and the world draw their potency precisely from the rejected and excluded possibilities, then the movement between the real and the possible - the use of critique - can hardly be provided with pathos and also not a voluntaristic decision of the subject, as Judith Butler emphasizes in her essay on Foucault's critique lecture: "One does not drive to the limits for a thrill experience, or because limits are dangerous and sexy, or because it brings us into a titillating proximity with evil." (Butler, 2002, p. 252). Butler emphasizes very clearly that critical articulations question the conditions of one's own being. Critical speech finds its seed and starting point in the fact that "One asks about the limits of ways of knowing because one has already run up against a crisis within the epistemological field in which one lives" (ibid.). The critical attitude of defending the eventfulness of any concept or term also questions the conditions of existence. This implies an epistemological problem: there is no neutral point of view from which the gender order or any other social categories and norms can be viewed and discussed. For the concern of critique therefore arises the problem of being entangled with the criticized. There is no neutral space and no neutral language, there are no neutral procedures in which the issue of gender order or any other category of identity could be dealt with. Focusing on gender order and its practical reinstitution and maintenance allows to see how norms, recognition and subjectivity interfere and are intertwined. In conclusion, and this is important to emphasise in view of the current political situation and the increased emergence of identity policy aspirations, it is precisely not a question of emending the one truth of gender or identity. Nor is it a question of arresting the power of language at the level of language politics. In a sense, language does not belong to the speaking individual, it is not the property of someone who has not already been taken into possession by language. In view of the current situation today and in the future, the most important thing is to fight for the differential nature of language, to remain sceptical about all fantasies of purity and limitation and to withdraw from blindly following the guidelines, grids and boundaries of language. It is also about questions of justice towards others and the other, from whose witness and encounter we can only distance ourselves at the price of an illusory and therefore violent immunization (Masschelein \& Simons, 2003).

\section{Conclusion}

In order to be able to take a critically problematic perspective on gender orders and their transformation, it may be important first and foremost not to keep them in an pedagogized end. 
Rather, it would be important to treat the contradictions and conflicts that arise as sources of another possibility, or even the impossible. Incidentally, Jacques Derrida (2005) writes that giving something to contradiction and conflict is the fundamental possibility and the enabling condition of the academic terrain of the university. This option is to be claimed as one is claimed by it: It is about arguing and seeking dissent; it is about questioning how the division of this space that we share is being undertaken (Rancière 2004). It is therefore a concept of transformation that has to do with the future (Wimmer 2014). "Are we not," Judith Butler (1997b, p. 162) asks accordingly at one point, "paralyzed by a fear of the unknown future of words that keeps us from interrogating the terms that we need to live, and taking the risk of living the terms that we keep in question?"

It is this gesture of question that is at issue in the criticism and transformation of discursive orders, such as that of gender. How to think and live a different order than the given one, how to deal with one's own participation in maintaining and finding one's place as a gendered subject - these questions do not only arise in academic contexts. They, on the contrary, refer to the profoundly modern problem from which pedagogy derives its status as science and profession: the fundamental and radical difference between the social order and the individual subject, which could only be brought to unity in a violent, manipulative and illusory manner. Modern pedagogy, as a science and profession, focuses precisely on this difference, so that the question will always be opened as to which limits lie in boundaries, offers and constraints of identity.

\section{References}

Austin, J. L. (1962). How to do Things with Words. London: Oxford University Press.

Bourdieu, P. (1991). Language and Symbolic Power. Cambridge Mass.: Harvard University Press.

Bourdieu, P. \& Passeron, J.-C. (1990). Reproduction in Education, Society, and Culture. London: Sage Publications.

Bröckling, U. (2004). Empowerment. In U. Bröckling, S. Krasman \& T. Lemke (Eds.), Glossar der Gegenwart (pp. 55-62). Frankfurt am Main: Suhrkamp.

Bröckling, U. (2007). Das unternehmerische Selbst. Soziologie einer Subjektivierungsform. Frankfurt am Main: Suhrkamp.

Butler, J. (1990). Gender Trouble. Feminism and the Subversion of Identity. New York \& London: Routledge.

Butler, J. (1993). Bodies that matter. On the discursive Limits of "Sex". New York \& London: Routledge.

Butler, J. (1997a). The psychic Life of Power. Theories on Subjection. Stanford, CA: Stanford University Press.

Butler, J. (1997b). Excitable Speech. A Politics of the Performative. New York and London: Routledge.

Butler, J. (2002). What is Critque? An Essay on Foucault's Virtue. In D. Ingram (Ed.), The Political: Readings in Continental Philosophy, (pp. 212-226). London: Basil Blackwell.

Casale, R. \& Forster, E. (2011) (Eds.). Ungleiche Geschlechtergleichheit. Geschlechterpolitik und Theorien des Humankapitals. Jahrbuch der Frauen- und Geschlechterforschung in der Erziehungswissenschaft Band 7. Opladen \& Farmington Hills: Barbara Budrich. 
Derrida, J. (1977). Signature Event Context. In J. Derrida, Limited Inc. (pp. 1-24). Evanston: Northwestern University Press.

Derrida, J. (2005). The Future of the Profession or the Unconditional University (Thanks to the "Humanities," What Could Take Place Tomorrow). In: Trifonas P.P., Peters M.A. (eds) Deconstructing Derrida (pp. 11-24). New York, NY: Palgrave Macmillan.

Foucault, M. (1970). The order of Things. An Archeology of the Human Sciences. New York: Pantheon Books.

Foucault, M. (1978). The History of Sexuality. Volume I: An Introduction. New York: Pantheon Books.

Freithofer, E. \& Hollerwöger, O. (2008). Diversity Management. In A. Dzierzbicka, \& A. Schirlbauer (Eds.). Pädagogisches Glossar der Gegenwart (pp. 79-87). Wien: Löcker.

Gomolla, M. \& Radtke, F.-O. (2009). Institutionelle Diskriminierung. Die Herstellung ethnischer Differenz in der Schule. Wiesbaden: VS.

Hetzel, A. (2011). Alterität und Anerkennung. Einleitende Bemerkungen. In A. Hetzel, D. Quadflieg \& H. Salaverría (Eds.). Alterität und Anerkennung (pp. 11-34). Baden Baden: Nomos.

Honneth, A. (1995). The Struggle for Recognition. The Moral Grammar of Social Conflicts. London: Polity Press.

Jergus, K (2015). Das Begehren der Norm(alisierung). Geschlecht in Wissenschaft und Forschung. In P. Bühler, E. Foster, S. Neumann \& D. Wrana (Eds.). Normalisierungen. Wittenberger Gespräche III (pp. 165-181), URL. http://www.pedocs.de/volltexte/2015/11330/pdf/Buehler_et_al_2015_Normalisierung en.pdf

Masschelein, J. \& Simons, M. (2003). Globale immuniteit. Een kleene cartografie van de Europese ruimte voor onderwijs [Global Immunity: A Small Cartography of the European Space for Education]. Leuven: Acco.

Rancière, J. (2004). The Politics of Aesthetics: The Distribution of the Sensible. London, New York: Continuum

Ricken, N. \& Balzer, N. (2010). Anerkennung als pädagogisches Problem. In A. Schäfer \& Ch. Thompson (Eds.). Anerkennung (pp. 35-87). Paderborn: Ferdinand Schöningh.

Tröhler, D. (2016). Educationalization of Social Problems and the Educationalization of the Modern World. In M. A. Peters (Ed.). Encyclopedia of Educational Philosophy and Theory, (DOI https://doi.org/10.1007/978-981-287-588-4), Singapore: Springer VS.

Wimmer, M. (2014). Pädagogik als Wissenschaft des Unmöglichen. Bildungsphilosophische Interventionen. Paderborn: Schöningh. 